$\left\{\begin{array}{l}\text { Division of AgricuIturaI Sciences } \\ \text { UNIVERSITY OF O C A I F OR NIA }\end{array}\right.$

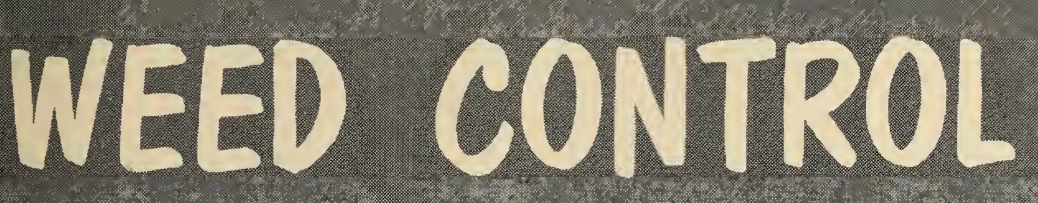

by SOIL STERILIZATION

ALDEN S. CRAFIS WILLAM A. HARVEY

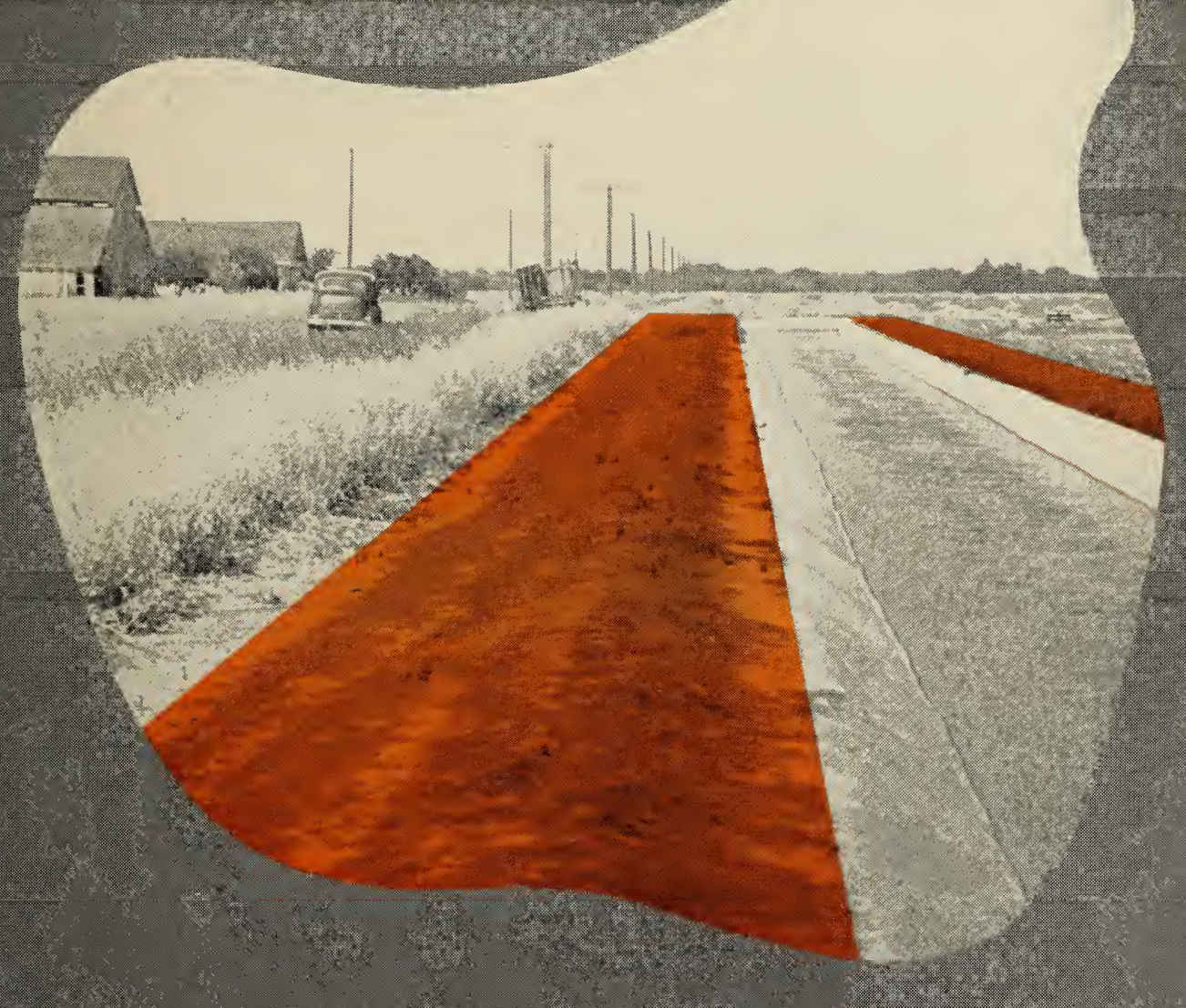

CALIFORNIA AGRICULTURAL Experiment Station Extension Service 


\section{SOIL

making the soil unfit for plant growth by chemical treatment-controls weeds more effectively than foliage sprays. It may be either temporary or permanent.

Temporary soil sterilants are effective for one year or less. They are used primarily to kill weeds on agricultural land that is to be returned to production.

Permanent soil sterilants provide complete and long-lasting destruction of all plant growth. They are important for

Agriculture-discouraging undesirable plant growth along irrigation ditches and fencelines, in corrals, and elsewhere;

Industry-eliminating weeds where they present operational hazards, such as along railroad rights-of-way, in lumberyards, and on airplane landing strips;

Public Works-blazing firebreaks, keeping highway guardrails clear, and improving the appearance of public roads, for example.

Successful soil sterilization depends upon these factors:

The susceptibility of the weeds to specific chemicals

The nature of the soil

Expected rainfall in the area

The properties of the chemical.

This circular describes the properties of the following major chemicals and tells where and how to use them:

Chloropicrin, p. 8

Carbon disulfide, p. 8

Methyl bromide, p. 9

2,4-D, p. 10

Sodium chlorate, p. 10
Borates, pp. 13 and 16

Sodium arsenite, p. 14

Arsenic trioxide, p. 14

CMU, p. 17

\section{THE AUTHORS:}

Alden S. Crafts is Professor of Botany and Botanist in the Experiment Station, Davis. William A. Harvey is Agriculturist in the Agricultural Extension Service, Davis.

APRIL, 1955 
Incomplete distribution. The chemical is fixed in the upper layer of soil, unable to penetrate to the deeper roots of the weed. This situation may be due to any one of several factors or to interaction among them:

1. A chemical of low solubility.

2. Clay soil or conditions such as hardpan or plowsole.

3. Inadequate rainfall or application at the wrong season.

A situation such as this would occur from the use of sodium chlorate against deeprooted perennials in clay soil with insufficient rainfall.

Partial sterilization. Although the chemical moves freely through the soil, it leaches out quickly and thus fails to effect a complete kill. Possible causes are:

1. A chemical of high solubility.

2. A sandy soil.

3. Excessive rainfall or irrigation, or application at the wrong season.

This situation would arise from the application of borates against shallow-rooted perennials and an above-average rainfall.
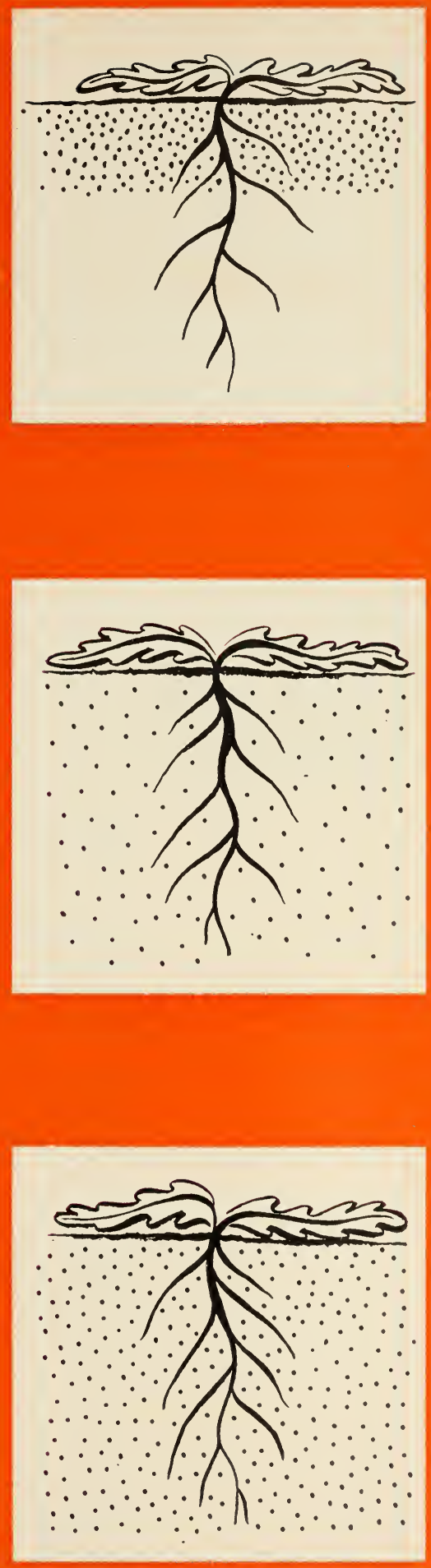

Complete sterilization. The chemical not only penetrates to the roots but remains in the soil long enough to be effective. In this case, a suitable chemical has been selected for the particular weed and soil type involved, and application has been made at the proper time of year in relation to rainfall.

Arsenic used against Bermudagrass in sandy loam, with intermittent rather than steady rainfall, is one example of such sterilization. 


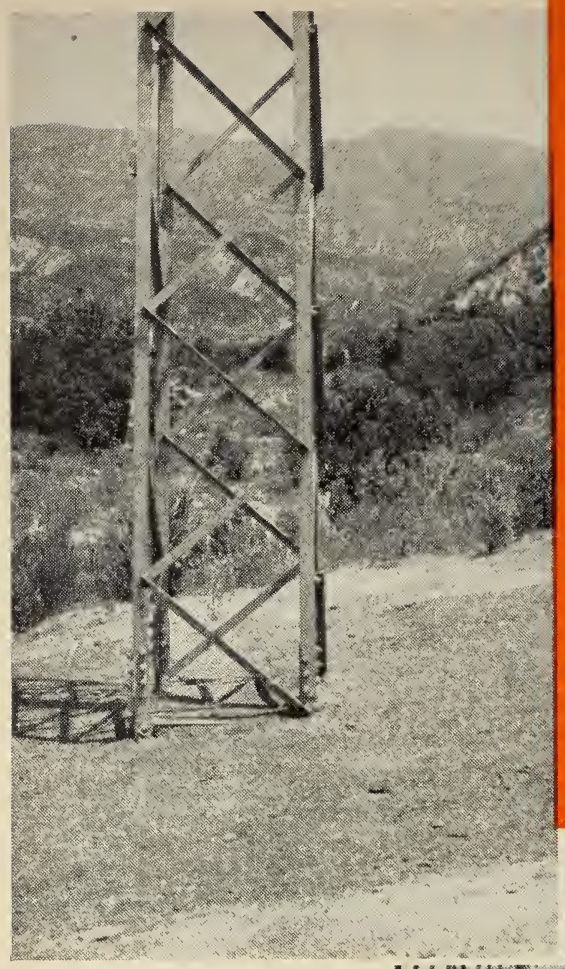

Around power transmission poles and railway structures, along irrigation ditchbanks, weed control by soil sterilization has proved effective and economical. Sterilization of irrigation ditchbanks means weed-seed-free water, controls weeds at the source. (Photograph upper left by H. D. Bruce, Calif. Forest and Range Exp. Sta., U. S. Forest Service.)

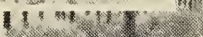

(2)
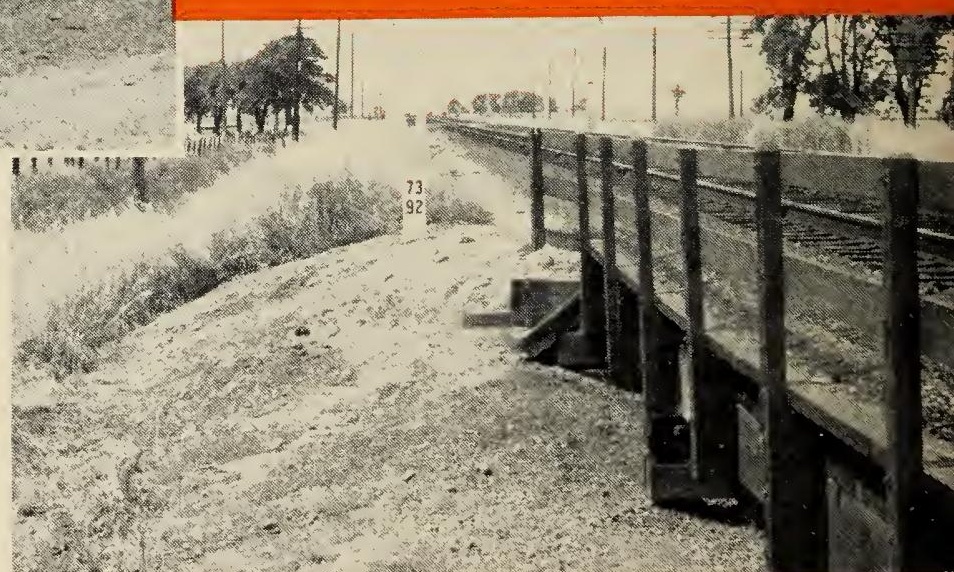

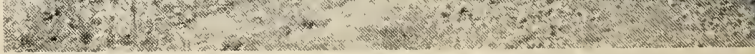

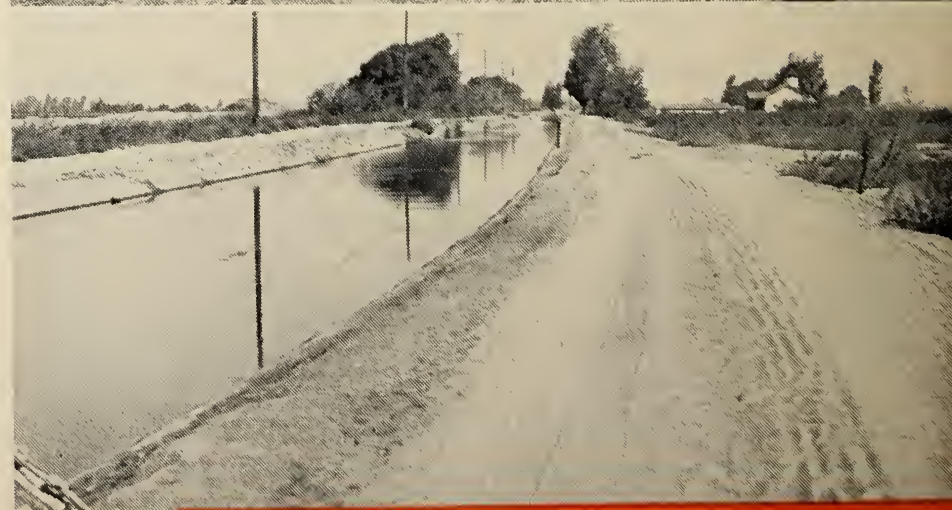




\title{
WEED CONTROL by SOIL STERILIZATION
}

\author{
Alden S. Crafts
}

William A. Harvey

$\mathrm{S}$ this circular, means treating the soil with chemicals to make it unsuitable for plant growth. The soil so treated may or may not be sterile in the sense that all soil micro-organisms-bacteria, fungi, nematodes, etc.-are also killed. Chemical soil sterilants have a wide variety of uses in weed control and their effect may be temporary or relatively permanent, depending on the chemical used and the amount applied.

Temporary soil sterilization is useful in controlling weeds on agricultural land to be returned to crop production. Permanent sterilization is useful for preventing weed growth on nonagricultural lands such as railroad ballast, irrigation ditches, fencelines, corrals, storage and parking areas.

Ideally, a spray that would translocate from the tops to the roots of weeds and kill them completely would be the best weedkiller to use. Practically, no such weedkiller is available. All the plants in an infestation may not have shoots above ground at the same time, and never are all plants in the same condition for treatment. With translocated sprays, including 2,4-D, a fringe of resprouting plants often persists around the border of treated patches and many plants within a patch may survive.

Advantages of soil sterilization are that all plants in an area may be killed and the length or persistence of the effect may be controlled by selection of the chemical and dosage. For example, carbon disulfide has been used for years to kill deep-rooted perennial weeds, and crops can be planted a few weeks after treatment. In contrast, arsenic, borax, chlorate, CMU, and other chemicals are being successfully used for long-lasting sterilization of nonagricultural soils.

Though having definite advantages, chemical soil sterilants also have limitations. Because of variety among chemicals, weeds, and soils, we need to understand how chemicals behave in different soils, how they act on different plants, and how temperature, rainfall, and soil composition affect their toxicity, their location in the soil, and their breakdown or loss from the soil.

\section{What determines the usefulness of a particular chemical?}

Studies of the effect of different chemicals in soils on the growth of plants already present and on other plants invading the treated soil show the following factors to be important in determining weedkilling properties.

1. Inherent toxicity. The nature and arrangement of atoms and molecules in some chemicals make them poisonous to plants. The exact way in which they kill plants is often not completely understood, but a number of chemical 
mechanisms may be involved. The amount of chemical necessary to reduce or prevent plant growth varies from a few pounds per acre to several thousand pounds, depending in part on the inherent toxicity of the chemical itself.

2. Adsorption. Some chemicals are attracted and adhere to the surface of soil colloids. Thus, in clay soils they may be so tightly held by the soil forces that they are not available to the plant roots even though present in the soil in sizeable amounts. In sandy soils the same amount of chemical might provide sterilization. Rates of application and even the choice of chemical itself will depend on the chemical's relative availability in different soil types.

3. Decomposition. Chemicals break down in different soils at different rates. This rate of breakdown may determine whether the most effective use of a chemical will be as a temporary or a relatively permanent sterilant. In some cases the breakdown products are themselves toxic to plants. The breakdown may be caused by bacteria or by chemical reaction in the soil and may be governed to a large extent by temperature and moisture.
4. Leaching. Distribution of the chemical throughout the root zone is necessary for satisfactory soil sterilization. Rainfall or irrigation moves the chemical within the soil.

Chemicals used as soil sterilants differ in solubility and in the ease with which they move. Soluble chemicals may give satisfactory results with relatively little rainfall and be leached or washed out of the soil with heavier rainfall. The less soluble chemicals may require considerable rain or irrigation to be effective. These differences will affect the date of application since some chemicals need most of the normal winter precipitation, while others would be entirely leached away and should not be applied until late winter or early spring to take advantage of only a portion of the winter rains.

5. Soil composition. Fertility, salt content, and acidity or alkalinity of soils all affect the toxicity and persistence of a soil sterilant. The choice of chemical may frequently depend upon its behavior in regard to these factors, and the amount necessary for sterilization may be governed by them as well.

\section{$\begin{array}{llllllllllllll}\text { P } & R & \text { E } & \text { V } & \text { E } & \text { N } & \text { T } & \text { I } & \text { V } & \text { E } & \text { W } & \text { E } & \text { E } & \text { D }\end{array}$}

A dirty ditch carries weed seeds onto farmland. Left, an untreated ditch; right, the treated portion of the left-hand bank shows the effect of soil sterilization on Russian thistle

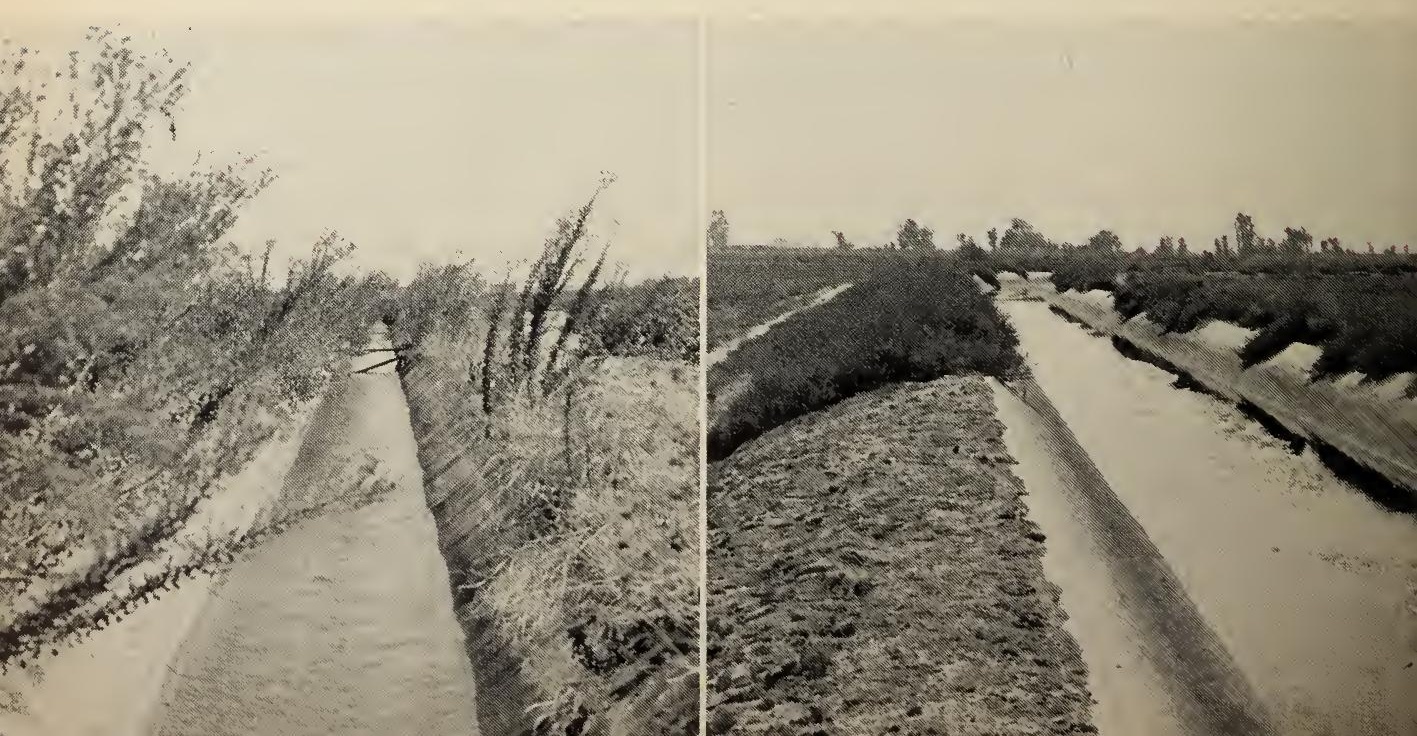


6. Species tolerance. Weed species vary widely in their inherent tolerance of chemicals. Most annual weeds, and many perennials, may be killed by merely cutting them off below the ground level. This is true of mustard, shepherd'spurse, pigweeds, lamb's-quarters, tumbleweed, and many others.

Certain other weeds sprout from pieces of stems or roots, or from the stump or crown: chickweed, crabgrass, knotgrass, periwinkle, hedge nettle, smartweed, and many woody species are of this type.

Most difficult to control are noxious perennial weeds, for these resprout from rhizomes or roots, even when cut deep below the soil surface. Such weeds are eradicated only where all living tissues are destroyed. In this group are wild morning-glory, hoary cress, Russian knapweed, white horse nettle, camel'sthorn, leafy spurge, and many others. Because of the deep and thorough distribution of their roots, soil sterilants must be incorporated in the soil throughout the layer containing roots or rootstocks in order to kill these weeds. The steri- lants must remain toxic long enough to effect a complete kill.

Though some tolerances relate to the distribution and regenerative vigor of roots, others are inherent in the nature of the plant cells themselves. For example, Klamath weed is highly susceptible to borax, but many bromegrasses tolerate high borax dosages; Russian knapweed responds readily to chlorate, but hoary cress is highly resistant to this chemical; knotweed resists arsenic but is easily killed by Endothal.

The interplay of these several factors determines whether a given chemical will kill shallow- or deep-rooted weeds, whether it will be temporary or relatively permanent, and, to a large degree, how much will be required to give satisfactory results. Successful soil sterilization results only when the chemical is distributed in the soil in the zone where the absorbing roots are located and at the time these roots are active. It must also be present in a lethal concentration for a long enough time to permit absorption of a killing quantity.

\section{$\begin{array}{llllllllllllllll}C & O & N & T & R & O & L & O & N & T & H & E & F & A & R & M\end{array}$}

Left: Sterilization of both banks the full length of a ditch provides preventive weed control. Right: Chemical treatment will keep even unlined laterals weed-free during winter and spring.

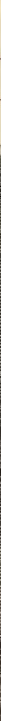




\section{TEMPORARY sol strenanrs}

Chemical treatments that sterilize the soil for one year or less are termed temporary soil sterilants. Such treatments are used primarily to kill perennial weeds on agricultural land. Since it is desirable to return such land to production as quickly as possible, the chemicals used should diffuse from the soil, decompose, or leach out readily. They should have no harmful effect on the soil but should, if possible, stimulate or nourish the crop plants.

\section{Chloropicrin}

Chloropicrin has proved valuable as a sterilant for potting, bedding, and other soils used in the greenhouse and nursery. It is a colorless, volatile liquid weighing 13.8 pounds per gallon. One pound contains $273 \mathrm{cc}$, or a little more than 9 fluid ounces.

It eliminates damping-off fungi, reduces the virulence of root rots, kills nematodes and other insects, and kills the seeds of many weeds. Seeds and nutlets of nutgrass are destroyed, and oxalis, spurge, and many other greenhouse pests are brought under control. Crop yields are often increased in soils treated with chloropicrin.

Application. Chloropicrin may be applied by means of a special tool, the Larvajector. Use 7 cc (about $1 / 4$ fluid ounce) per cubic foot of soil, 1 pound for 39 cubic feet, or 1 pint for 64 cubic feet. The soil should be damp at the time of treatment and should have a temperature above $65^{\circ} \mathrm{F}$. Because it permeates the soil as a toxic vapor, it should be uniformly distributed throughout the soil mass. Soil in piles may be treated by injection and then covered with a glue-coated vaporproof paper, wet canvas, or a plastic sheet to prevent vapor loss. Flats may be treated individually, quickly piled, and covered.

\section{Carbon disulfide.}

Carbon disulfide is a clear, volatile liquid that vaporizes in the soil and produces a poisonous gas, extremely toxic to plant tissues. It weighs 10 pounds per gallon. It has been used in California for more than 25 years to kill wild morning-glory and other deep-rooted perennial weeds.

Soil conditions are the primary factors involved in the successful use of carbon disulfide as a herbicide. Greenhouse studies and field tests have shown that carbon disulfide kills by contact. Therefore, to be effective it must be thoroughly distributed in the soil. Tests on the movement of carbon disulfide vapor through columns of field soils showed that high soil moisture, plowsole, hardpan, and compacted clay layers restrict flow of the gas and limit its distribution.

Plowsole is the commonest barrier that restricts movement, but this condition can usually be corrected by breaking up the compacted layer with a subsoiler. In clay soils, carbon disulfide moves slowly and to a certain extent is adsorbed. Such soils require increased dosage and close spacing of injections.

Application. The common practice with carbon disulfide is to inject the liquid into holes staggered in rows and spaced 18 inches apart in each direction. Injections can be made by pouring the liquid from a measuring cup into a long funnel that reaches deep into the hole in the soil. The chemical may also be applied by hand with.a Mack IVeed Gun or mechanically with a tractor-drawn subsoiler equipped with tank, pumps. and injection tubes. The usual depth of injection is 6 inches, but shallower treatment may be used if surface sealing is well done. 
Carbon disulfide develops a definite vapor pressure in the soil, and loss of vapor from the soil surface must be prevented. This may be done by rolling the soil surface or by sealing it with surface sprinkling. Carbon disulfide vapor is heavier than air and moves downward in the soil, killing deep roots. Some shallow tillage is sometimes necessary to kill surface roots of perennial weeds after treatment with carbon disulfide.

Do not apply carbon disulfide during high winds. These ventilate the soil and cause excessive loss of vapor.

Dosage. The usual dosage is 2 ounces per hole-the equivalent of 20 pounds per square rod, or 3,200 pounds per acre. In heavy soils, the dosage is increased by using 2-ounce injections with 15- or even 12-inch spacing. In certain light soils that can be sealed satisfactorily, dosage may be lowered by increasing the spacing to 24 inches.

CAUTION: Carbon disulfide vapor is inflammable. When mixed with air, it is explosive. Drums should be grounded while liquid is being drawn from them. Even empty drums are dangerous, for vapor may ignite by static discharge. Do not smoke while working with carbon disulfide.

\section{Methyl bromide}

Methyl bromide has recently been introduced as a soil fumigant and weed- killer. A mixture containing 98 per cent methyl bromide and 2 per cent chloropicrin is sold as Dowfume MC-2. This product has proved effective for controlling insects, plant diseases, and weeds in tobacco and vegetable seedbeds, as well as in potting and bedding soils of nurseries and greenhouses. It is very effective against nutgrass. Do not use it in wet, soggy soil.

Application. Methyl bromide is a liquid that boils at $40^{\circ} \mathrm{F}$ to form a penetrating vapor. Because of its volatility it must be retained in treated soils by covering with a plastic tarp. For ordinary-scale application the fumigant is introduced through one centrally located inlet in the covering at a dosage rate of $1 \frac{1}{2}$ pounds per 100 cubic feet of piled soil, or per 100 square feet of soil surface for flat treatment. After 24 hours the cover may be removed, and the soil is ready to plant as soon as the vapor escapes. Chloropicrin is included in MC-2 so the user can detect leaks in the apparatus and dissipation of the gas from the treated soil.

CAUTION: Methyl bromide is very poisonous. Follow carefully the directions printed on the container.

\section{Other volatile soil sterilants}

A number of other volatile chemicals have been tested as soil sterilants in-
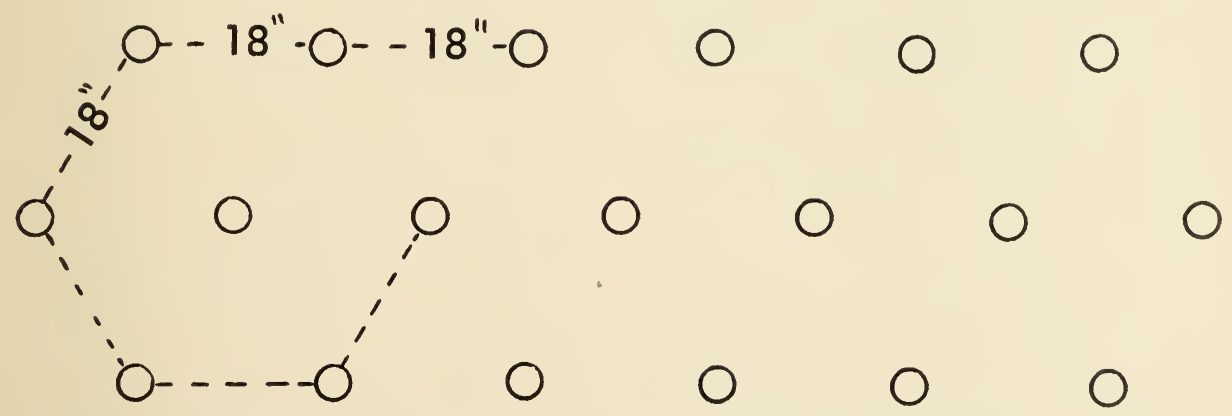

The above diagram illustrates spacing for carbon disulfide injections. 
cluding ethylene and propylene oxides, DD (dichloropropane-dichloropropene mixture), tetrachloroethane, and ethylene dibromide. Though effective, none of these has proved so popular as the three described above. Possibly one of these or some other soil fumigant may become widely used in the future.

\section{2,4-D}

Tests have proved that 2,4-D absorbed from the soil by roots is effective as a weedkiller. Though more effective and convenient when used as a foliage spray, 2,4-D may act as a selective soil sterilant, and in some cases this use is preferred. As a pre-emergence herbicide, 2,4-D may combine contact action on emerged weed seedlings with sterilant action through the soil on germinating weed seeds. For this to take place, rainfall or sprinkler irrigation is necessary to wash the chemical into the topsoil. Through the soil 2,4-D is particularly effective, and its use under certain conditions has been spectacular, for it will even kill seedlings of such pests as crabgrass, watergrass, and foxtail.

2,4 -D is being used as a pre-emergence treatment in sweet corn at $1 / 2$ to $3 / 4$ pound per acre, and in field corn at dosages up to $1 \frac{1}{2}$ pounds per acre. Some hybrid corn varieties are susceptible to 2,4-D injury; this should be kept in mind when this weed-control method is used. Other crops that have been so treated are milo, sorghum, Sudangrass, and strawberries. In the latter crop, Crag 1, a modified form of 2,4-D having no contact action, has proved to be an excellent weedkiller if washed into the topsoil by rainfall or sprinkler irrigation.

In controlling perennial weeds, 2,4-D is ordinarily used as a translocated spray. However, where the residue from the spray is washed into the soil, the chemical may have a toxic effect on the roots.

\section{Sodium chlorate}

Sodium chlorate has been widely used as a weedkiller for over 20 years. It is inexpensive and relatively nontoxic to human beings and animals. It has been used:

1. As a contact spray, at a concentration of about 2 per cent, to kill mixed weed populations on nonagricultural areas (roadsides, fencelines, rights-ofway).

2. As a translocated spray, applied as a wetting spray at a rate of 1 pound per gallon of water. Used under proper conditions, it will translocate to the roots. of perennial weeds and kill them to some depth.

3. As a temporary soil sterilant washed into the soil by rains or irrigation, chlorate is absorbed by the roots of weeds and kills the plants.

Influence of soil, plant, and climate. Chlorate is not readily absorbed by plant roots in the presence of high nitrate concentrations. Chlorides, sulfates, and possibly phosphates have similar but less marked influence. Fertile soils (high in nitrates) and saline soils (high in salts) require high dosages of chlorate.

Heavy soils usually require more chlorate than sandy ones, and for a given rainfall, penetration of water and chlorate is less in heavy soils.

Where chlorate-tolerant plants are treated, high dosages are required. Hoary cress, alkali mallow, wild heliotrope, and camel's-thorn are examples.

In regions of low rainfall, both moisture distribution and nitrate concentration may influence the effectiveness of chlorate. Because it is active only in moist soil through absorbing roots, dormant roots in soil of low moisture content are not affected by chlorate. Nitrates that have accumulated during the dry season are concentrated in the lower part of the moist soil layer. Thus, chlorate restricted to a shallow layer of soil 


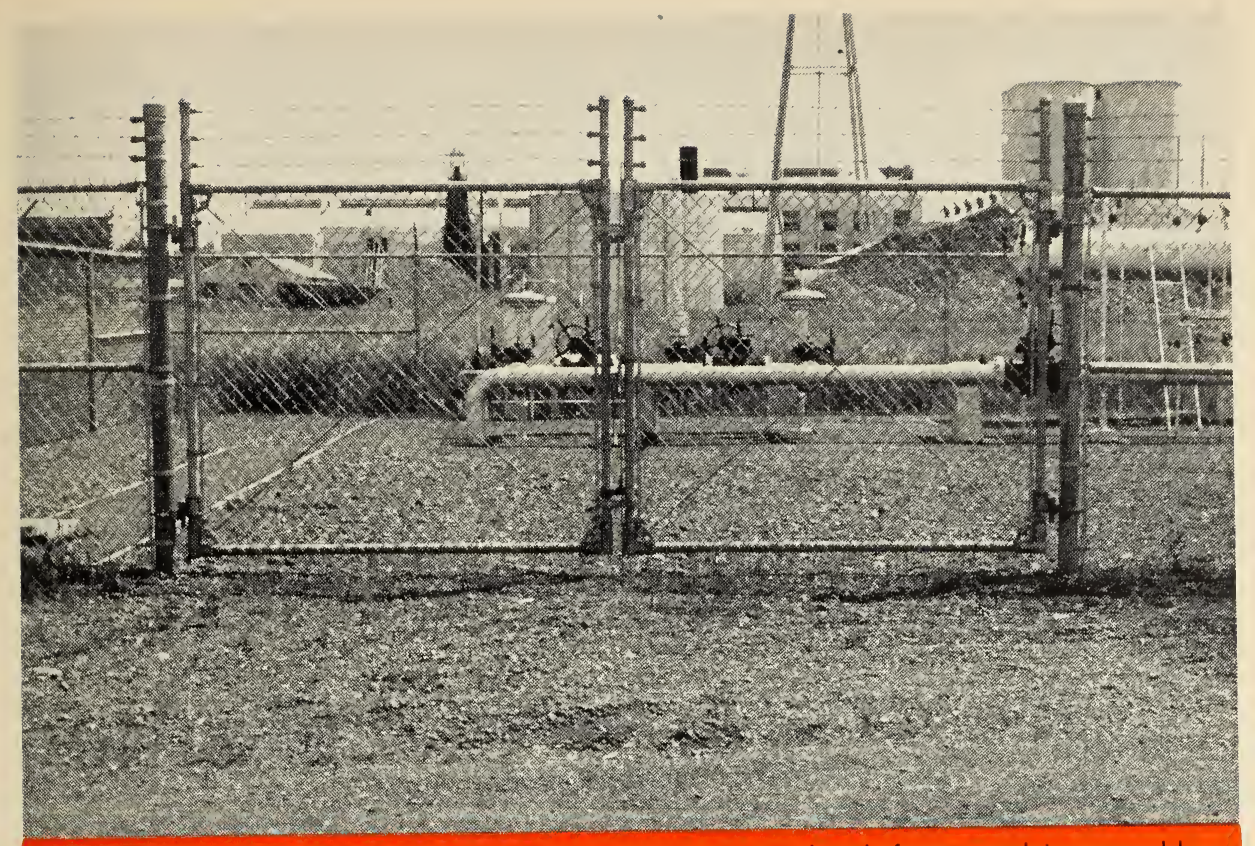

Transformer yards, gas wells and meters, oil pipelines, oil-tank farms, and innumerable industrial sites constitute an immense market for chemical soil sterilants.

\section{$\begin{array}{llllllllllllllll}\text { I } & \text { N } & \text { D } & \text { U } & \text { S } & \text { T } & \text { R } & \text { I } & \text { A } & \text { L } & \text { U } & \text { S } & E & R & S\end{array}$}

Elimiration of weeds in a lumberyard reduces fire hazard, makes stacking and removal more convenient, and greatly improves the appearance of the yard. (Photograph by Peter Van den Bosch.)

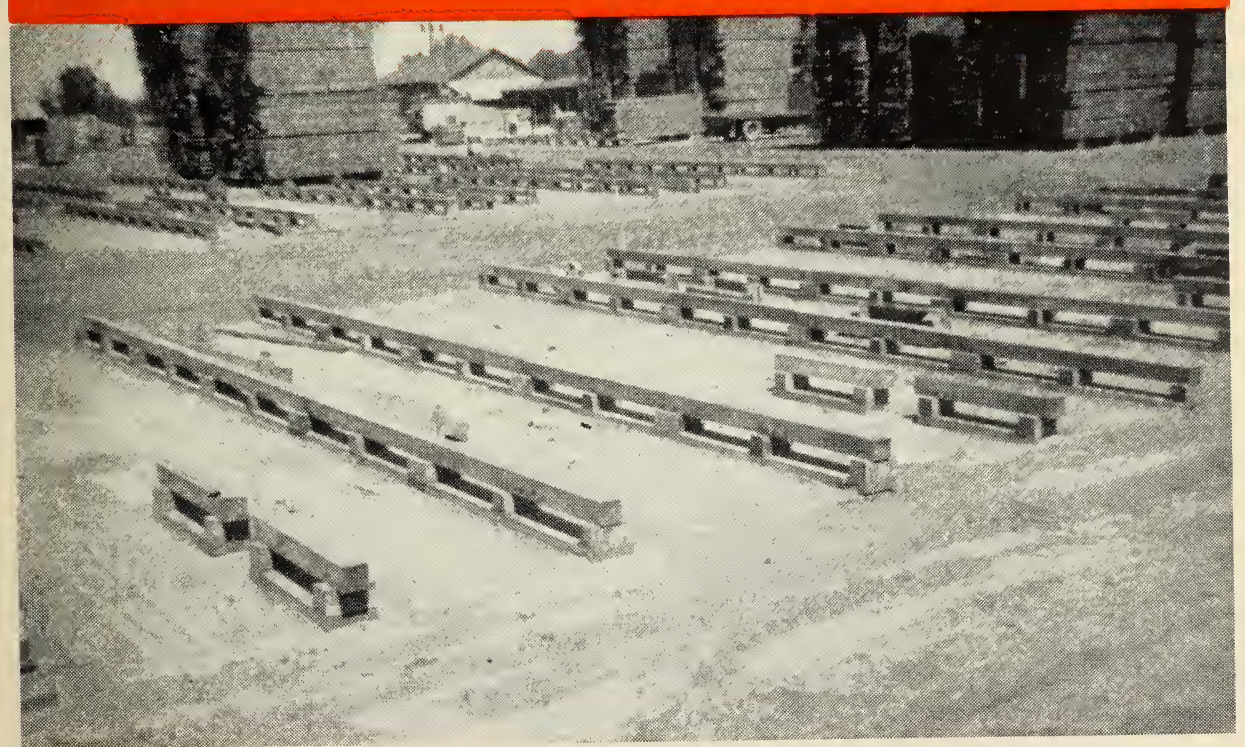


may only partially kill the weeds; roots surviving below may produce resprouts that push up to the top and grow.

In regions where rainfall is ample, especially in summer, chlorates are distributed rapidly throughout a deep, moist zone, and nitrates have little chance to accumulate. For this reason, chlorate applied at 1 pound or so per square rod may kill wild morning-glory in one locality and have little or no effect in another. Similarly, light chlorate applications may control weed species on leached primary soils, while heavier applications on rich, recent alluvial soils will have little effect.

The rate at which chlorate decomposes in the soil is affected by moisture and temperature. In humid regions, there is little difficulty with chlorate residues. In dry regions, where chlorates tend to remain in the soil, the best way to remove them is by leaching. On crop lands where irrigation is not possible, chlorates must be used with caution.
Application. Because of the variations in susceptibility of weed species to chlorate and the relationship of toxicity to soils and climate, there is no "best" method for using chlorate in California. Methods must be determined by local situations.

Three methods are feasible:

1. Fall spraying, where part of the chemical translocates from the tops to the roots of the weeds and part is leached into the soil by winter rains to be absorbed by the roots. In this method a solution containing 1 or more pounds of chlorate per gallon of water should be sprayed on the weeds to insure prompt penetration.

2. Direct soil treatment in winter. The chemical may be applied dry if uniform distribution can be accomplished.

3: Spring soil treatment or spray followed by spring rains or irrigation. Here concentration is not so important, but rainfall or irrigation to leach the chemical into the topsoil is essential.

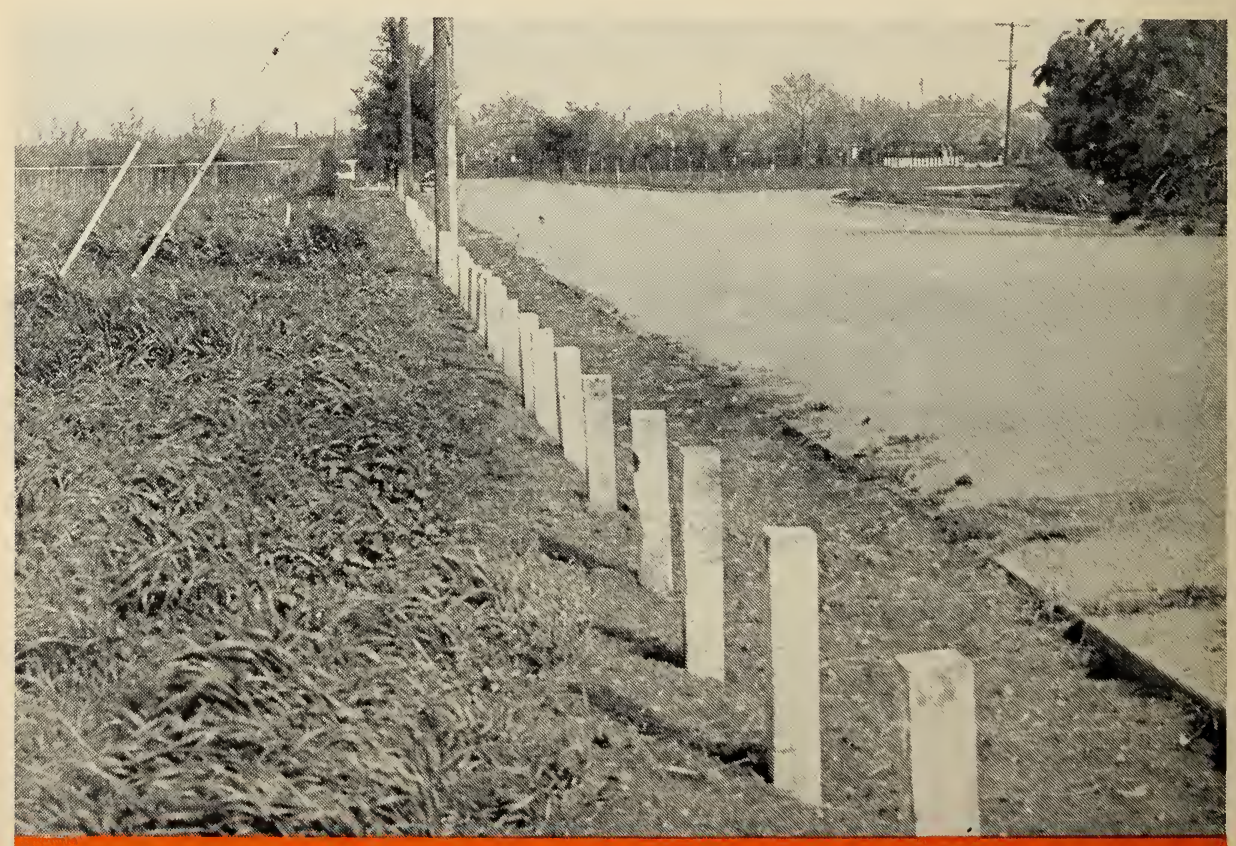

Soil sterilization along guardrails makes for a neat appearance and prevents the spread of weeds along highways. 
Dosage. The general recommendations for chlorate dosage range from 1 to 6 pounds per square rod. This wide range represents the adjustments that must be made to take care of differences in soil fertility, soil texture, species tolerance, and variations in rainfall.

The old recommended dosage of 3 pounds per square rod, applied in 3 gallons of water, is a good average figure. But for wild morning-glory at Davis it is not enough-4 to 6 pounds is required. In one situation, 8 pounds of chlorate did not kill hoary cress in a Yolo soil, whereas 4 pounds was enough on a Montezuma adobe clay. Bermudagrass was killed by 2 pounds per square rod in Fresno sandy loam, but not by 8 pounds in Yolo clay at Davis. These examples show the problem involved in recommending chlorate dosages. The best solution is to make small field trials under local conditions.

CAUTION: When mixed with organic matter, such as straw, wood, or clothing, sodium chlorate forms an easily ignited, highly inflammable mixture. Keep chlorate stored in metal containers. It should be used with extreme care, by people fully aware of the danger involved. In case of fire do not try to smother the blaze; use water to flood it.

Altacide is a proprietary mixture of sodium chlorate with other chemicals that reduce its fire hazard. Dosage of this and similar chlorate mixtures should be determined by their chlorate content.

\section{Borates}

In regions of low rainfall borates are used for permanent soil sterilization; where the annual rainfall is 25 inches or more they leach out of the topsoil and cause only temporary sterilization. Borax, borate ores, and borax-chlorate mixtures have been used to control St. Johnswort (Klamath weed). Often after this pest has been eliminated, the grass crop that follows on the treated soil may be considerably stimulated as a result of the treatment.

Boron compounds are available in several forms for use as weedkillersborax (sodium tetraborate), sodium pentaborate, borascu (a concentrated borate ore), anhydrous razorite, and several borate-chlorate mixtures. Borate toxicity depends upon soil properties. In general, toxicity is high in sandy soils and low in clays and adobe clays.

Borates remain in effective concentration in the topsoil during the first 4 to 10 inches of rainfall. With continued rains the chemical is leached, and it becomes less effective against shallowrooted perennials. In applying borates it is best to count on average rainfall. If rainfall is below normal, a few perennials may survive; if above normal, more chemical should be applied before the end of the rainy season.

Application. Borate dosage varies from 10 to 30 pounds or more per square rod, depending on soil type, rainfall, and species susceptibility. Application of borascu, razorite, and often borax is in the dry form. Machine application is more uniform, but hand application is satisfactory if carefully done. Sodium pentaborate and water-soluble boratechlorate mixtures are commonly applied by machine as sprays.

Borate-chlorate mixtures are becoming increasingly popular as soil sterilants. They combine the rapid action of sodium chlorate with the more persistent toxicity of the borates. In addition, they have the obvious advantage of being relatively nonhazardous from the standpoint of inflammability, the borate counteracting the high nxidation and easy ignition of sodium chlorate when it is in contact with organic matter. Because these mixtures are safe to use, they are becoming increasingly popular for treating playgrounds, highway and ditch systems, parking areas, industrial sites, and other areas where a nonhazardous material is needed. 


\section{PERMANENT ${ }_{\text {STERILANTS }}^{\text {SOI }}$}

Complete and lasting destruction of all plant growth is sometimes desirable in certain areas such as ditchbanks, fencelines, and many industrial sites. Several chemicals are convenient and effective for this purpose.

\section{Sodium arsenite}

Sodium arsenite is the active ingredient in the old "weedkiller" solutions. Its toxicity is greatest in light, sandy soils and least in heavy clay. For example, on Fresno sandy loam 2 pounds of sodium arsenite is as effective as 8 pounds on Yolo clay.

Most soils retain arsenic in an available form. The amount retained depends upon soil texture (highest in heavy soils) and dosage. Arsenic in most types of soil does not leach out readily; 60 surface inches of water failed to remove all arsenic from the top three feet of medium- to heavy-textured soils. However, 16 surface inches of water removed it from Fresno sandy loam. Arsenic (as sodium arsenite) applied at the rate of 4 pounds per square rod killed Bermudagrass in the Fresno soil but not in Yolo clay loam. Tests showed that arsenic was present in the sandy soil to a depth of 12 inches or more after the first winter rains. In the Yolo soil it was all in the top four inches, and grass rhizomes survived below this depth.

On test plots 4 pounds of arsenic (as sodium arsenite) per square rod made Fresno sandy loam sterile for four years. Rainfall during that time was sufficient to leach the chemical from the topsoil, but because the rain was intermittent rather than steady, the arsenic was retained at a toxic concentration. This is a factor to consider when gauging the effect of rainfall on sterilized soils.
Application. Light, intermittent rains will not leach out the chemical so effectively as steady rains or flooding. Therefore, dosage and type of application must be adapted to climatic conditions as well as to soil type. The most practical way to meet these conditions is to apply sodium arsenite to the soil at a rate equivalent to 4 pounds of arsenic trioxide per square rod, and to repeat the application as often as necessary to maintain a sterile condition. Where rainfall is heavy, light annual applications of chemical are most economical, as this avoids excessive loss by leaching. In drier regions, one heavy application may be effective for four years or more.

You can buy sodium arsenite as a dry powder or in a stock solution ready to dilute to field strength. It comes in two concentrations. The 8-pound solution contains 50 per cent arsenic trioxide by weight and weighs 16 pounds per gallon. The 4-pound solution contains 30 per cent arsenic trioxide and weighs 12 pounds per gallon. To apply the proper dosage, you need to know the strength of the solution.

\section{Arsenic trioxide}

Arsenic trioxide has several advantages over sodium arsenite as a soil sterilant:

1. It is not attractive to livestock, whereas sodium arsenite is. It can be used with relative safety if applied as soon as the containers are opened, but should not be left in open containers where animals have access to it.

2. Being relatively low in solubility, it persists in the soil for a long period; its sterilizing effects have been visible as long as 15 years after application. 
3. Being a by-product, it is the least expensive form of arsenic available.

4. A dry, friable powder, it can be applied dry by hand or by means of a mechanical spreader or a fertilizer spreader modified to give even and uniform distribution.

The low solubility has one disadvantage: the chemical is slow in action and may not be effective during the year it is applied. This can be remedied by mixing it with chlorate or CMU to give quick sterilization during the first year. Its solubility can also be enhanced by the addition of a modern detergent. Furthermore, if a liquid detergent is used, the material is less dusty and hence safer to apply.

Using chlorate with arsenic trioxide not only gives quick effects but is advantageous where deep-rooted perennials are involved. The chlorate handles the perennials, and then the arsenic prevents the establishment of seedlings of both annual and perennial weeds.
The dry arsenic treatment is recommended as a follow-up after the use of sodium arsenite or any other type of soil sterilant. It can be used while the original sterilant is still effective, and its persistence makes for long-lasting sterility of the treated area.

Pelleted arsenic trioxide has been tested experimentally and has proved very effective. Not only are the pellets easy to apply and lacking in dustiness; in addition, they roll into the crevices in gravel or ballast and concentrate the arsenic where the weed seeds germinate. Pelleted arsenic has proved particularly effective in long-lasting sterilization of railway ballast.

Some plant species have proved to be resistant to the toxic action of arsenic in the soil. Several salt bushes (Atriplex sp.), Russian thistle (Salsola kali), yellow star thistle (Centaurea solstitialis), knotweed (Polygonum aviculare), and grasses such as beardless wild rye (Ely. mus triticoides) are notable among these.

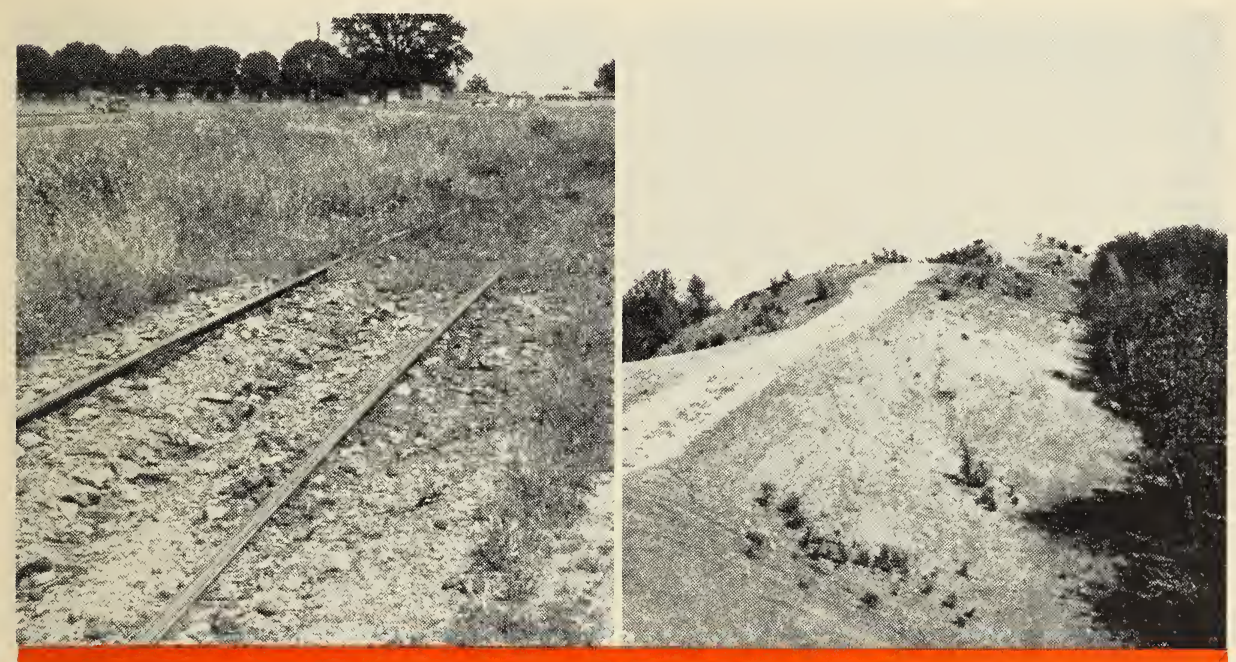

Soil sterilization with arsenic trioxide. Left: The pelleted form has been used in this test strip in railroad ballast. Right: Dry arsenic trioxide applied along a firebreak io provide a backfire strip may be effective for five years or more (photograph by D. H. Bruce, Calif. Forest Range Exp. Sta., U. S. Forest Service). 


\section{Borates}

Boron in sufficient quantity and in forms available to plants will sterilize any soil. Borates are less firmly fixed in soils than arsenic and therefore do not last so long. Repeated applications, however, will result in fairly permanent sterility.

A great advantage of borates is that they are not poisonous to animals or humans, and hence may be used without danger around public places such as playgrounds, airports, and race tracks.
Borate toxicity depends upon soil texture; its movement into and leaching out of the soil depends upon rainfall. Toxicity is high in coarse, sandy soils and low in clays. Although borates are retained in the soil, they lose toxicity with long contact.

Application. A practical method for using borates is to apply them annually or oftener until enough is built up in the soil to result in relatively permanent sterility. The dosage or number of applications may then be reduced. Use of

\section{CAUTIONS FOR USE OF ARSENICALS:}

\section{Arsenic in any form is poisonous. Handle with care.}

Do not store mixtures of dry white arsenic and dry sodium chlorate. They may ignite spontaneously.

Animals are attracted to sodium arsenite. Never apply it in any form to vegetation where livestock may graze. To prevent stock poisoning, use sodium arsenite only on bare soil that has been cleared of all plant growth.

Apply sodium arsenite in late fall or early winter; rains soon wash it into the topsoil, or snow will cover it. Keep livestock off treated areas until two or more inches of rain have fallen.

Post "Poison" notices in all areas treated with sodium arsenite.

Where arsenic is being used on public lands or in irrigation or drainage districts, lawsuits and actual losses may be avoided by obtaining waivers from property owners or tenants having land adjacent to the treated areas.

Do not let arsenic come into contact with the skin. It may cause a rash. Individuals vary widely in their susceptibility to arsenic poisoning. If you develop a rash from slight con- tact with arsenic, do not work with the chemical in any form. Where contact with arsenical sprays or dry arsenic dust is unavoidable, protect exposed skin and lips with Vaseline.

Arsenical solutions in the body are highly poisonous. Symptoms of arsenic poisoning are: nausea, vomiting, diarrhea, intestinal pain, and scanty, burning urine. Small amounts of arsenic taken into the body over a long period of time may result in the following chronic symptoms: muscular weakness, scanty, burning urine, and intestinal disturbances. If these are present, consult a doctor.

If arsenic is accidentally swallowed, call a doctor immediately. Meanwhile cause vomiting by giving raw eggs, milk, and thin flour and water paste.

In spite of its hazardous nature, arsenic is handled in thousands of tons annually in smelters and refineries. Tremendous amounts are applied by agriculturists as insecticides in the form of lead arsenate and calcium arsenate. If proper precautions are taken, it can be handled with safety. 
the less soluble form also prolongs the sterilizing effects.

On most soils, dosages of 10 to 40 pounds per square rod are suggested. Adding one part of sodium chlorate in four to nine parts of borate increases considerably the initial effectiveness of the treatment. This mixture may be necessary where boron-tolerant weeds, such as some weedy bromegrasses, are present. Several borate-chlorate mixtures are now on the market. These may be used, particularly for the initial treatment, if an adequate quantity of borate is applied.

Finely ground borate or borate-chlorate mixtures may be applied dry by hand or by means of a fertilizer or herbicide spreader. Use borates with caution around trees, shrubs, or vines. The leaching of small amounts of these chemicals into the feeding roots of such plants may cause chlorosis or dieback. It is best to keep well beyond the spread of branches of valuable plants in applying borate sterilants.

\section{CMU*}

CMU is a new organic soil sterilant of great promise. It is a nonvolatile, noncorrosive, nonflammable, insoluble powder, applied in suspension in water. Dosage rates have not been accurately determined under all soil and climatic conditions, but amounts from 20 to 80 pounds per acre are recommended, the higher rates being required for heavy soils or where perennial weeds are involved. At present CMU seems most useful against annual weeds in California.

Because CMU has been tested for only four years in the field, its persistence in soils is not known for a wide range of

* CMU is the designation temporarily assigned to the chemical 3-(parachlorophenyl)1,1-dimethyl urea. This chemical is manufactured by Du Pont and sold under the trade names of Telvar W and Karmex W. Several analogues have been tested and some of these may be marketed in the future. conditions; applied at the higher dosage rates it apparently lasts through two or more years. Greenhouse tests prove CMU to be more resistant to breakdown in the soil than other soil sterilants so far tested. In the field it is the only soil sterilant that maintains sterility below the water line in irrigation ditches after water has been turned in. Extensive tests show that CMU presents no poison hazard to human beings or animals under ordinary conditions of use. Apparently the only precaution necessary is the same as described above for borates: it should not be applied close to the spreading roots of valuable trees and shrubs.

\section{Other Sterilants}

Among the new chemicals being tested as herbicides, a number are effective through the soil and hence useful as soil sterilants. Since most of them are somewhat selective, it is necessary to know which weeds they kill in order to use them successfully. Combinations often prove better than single chemicals.

For temporary use before planting a crop, cyanamide has long been used. More recently a combination of IPC and 2,4-D has been recommended. In warm, moist soils both of these materials break down within a few weeks; in winter they may remain active for several months. For the most lasting effects the wettable IPC should be combined with 2,4-D acid. Chloro IPC is even more lasting than the wettable powdered IPC.

Use of temporary soil sterilants by the pre-emergence method involves applying the chemical to the soil before the crop emerges. This system of sterilization de-

IN BRIEF ...

For quick reference, the chart on the next two pages sums up

Soil sterilants in common use,

How they act in the soil,

Where and how to use them. 


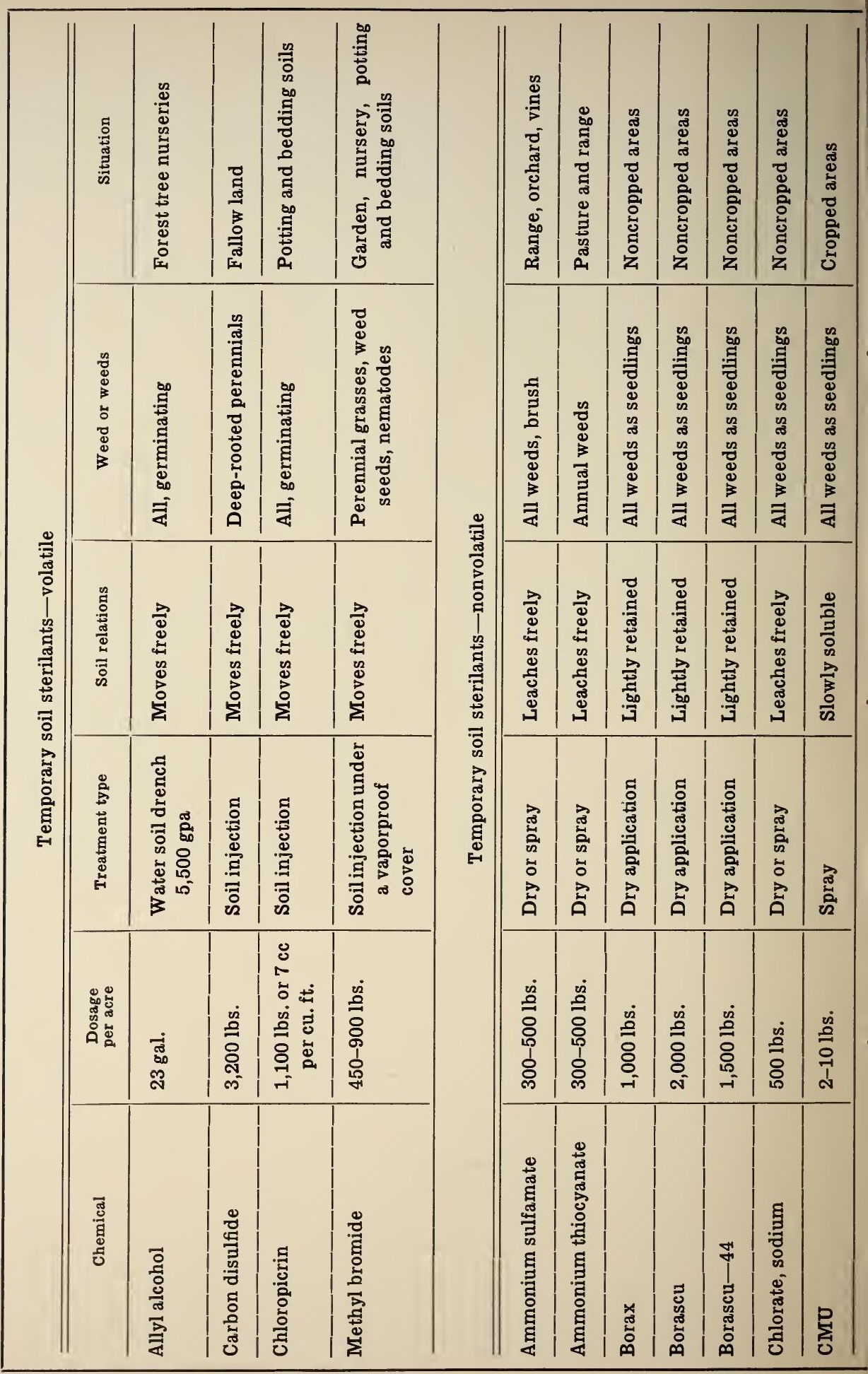




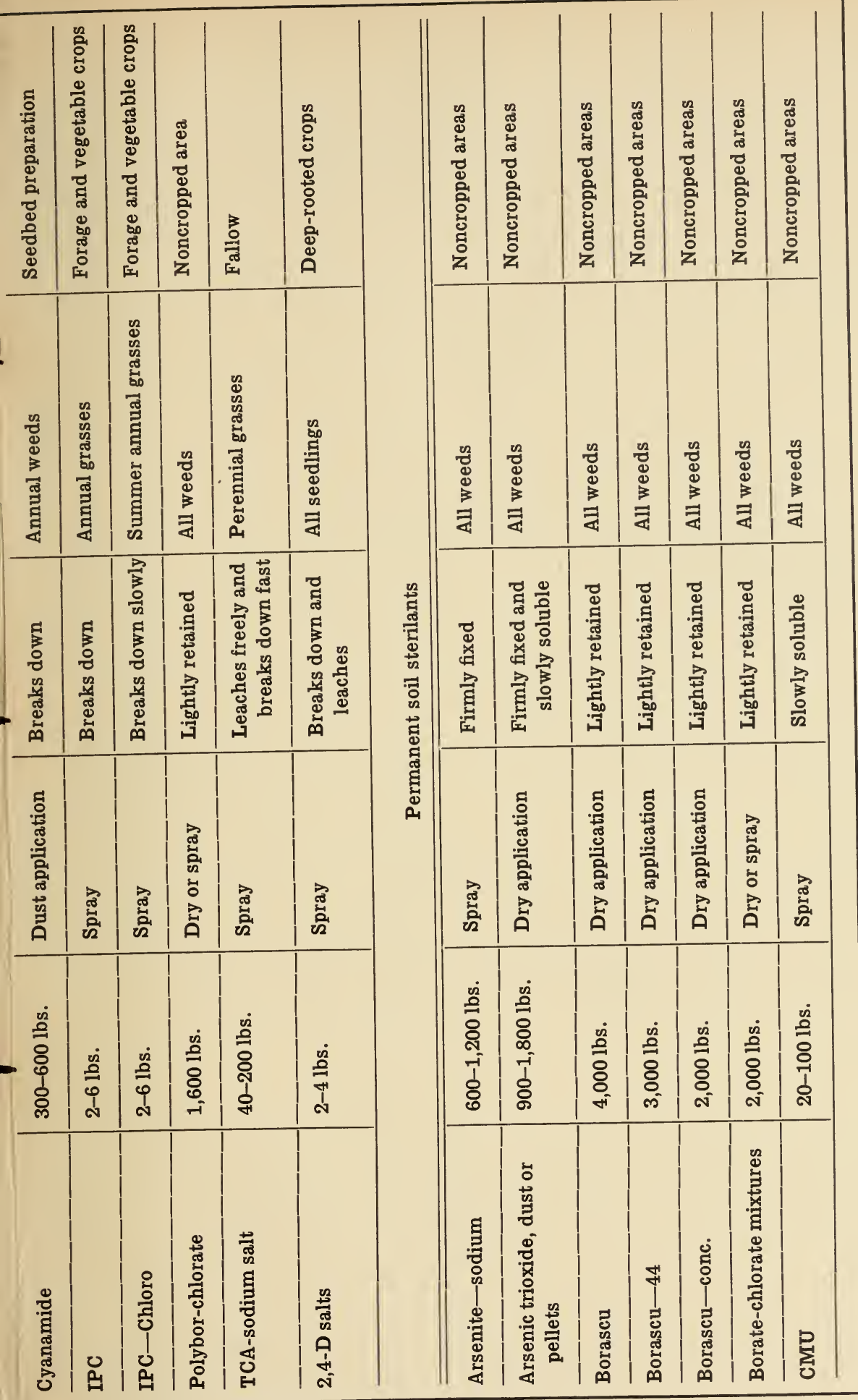


pends upon rapid breakdown or some sort of selective action so that the weeds are controlled without injury to the crop. Some chemicals used in this way are cyanamide, sodium pentachlorophenate, dinitro compounds, 2,4-D, IPC, Chloro IPC, Crag 1, Endothal, and CMU. Because the pre-emergence method represents a very specialized type of soil sterilization, it cannot be treated in detail in this circular.

Endothal is another herbicide that is active through the soil. In combination with 2,4-D acid it may provide sterilization for some time. Naphthyl phthalamic acid and sodium pentachlorophenate are additional organic sterilants.

Since all of these organic materials have some selective action, they require careful testing in any new situations to learn their action under local conditions. With proper precautions and accurate knowledge of their selectivities, they may be used singly or in combination to provide soil sterilization under a wide variety of conditions.

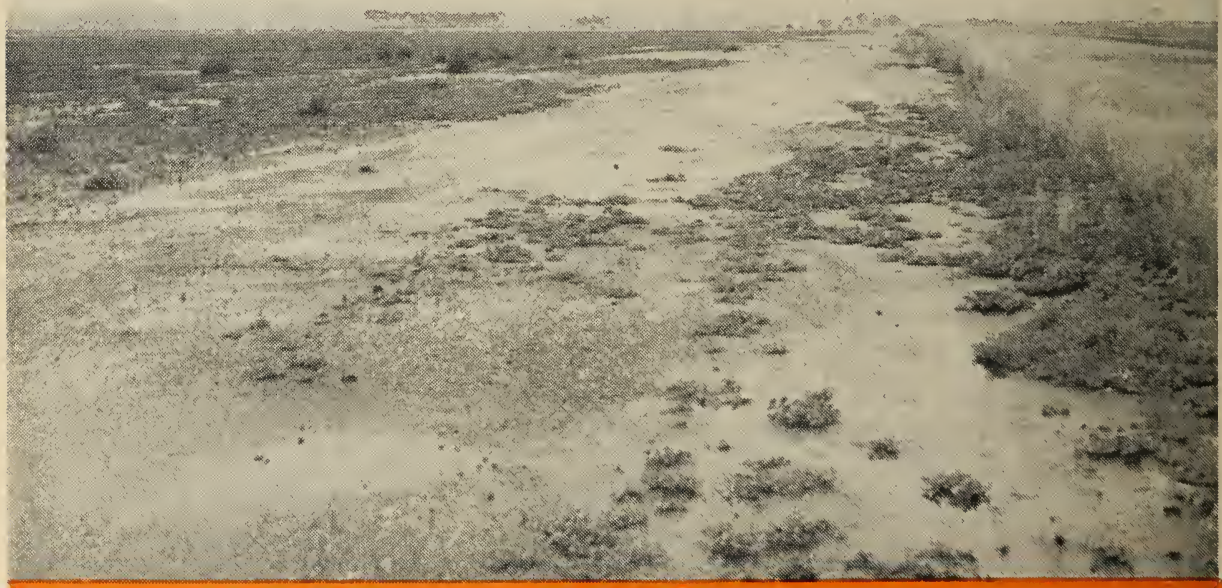

Weed encroachment on an airplane landing strip. Chemical soil sterilization at the time the strip was paved could have prevented this costly loss. (Photograph courtesy of the Public Works Office, Eleventh Naval District, San Diego, Calif.)

In order that the information in our publications may be more intelligible it is sometimes necessary to use trade names of products or equipment rather than complicated descriptive or chemical identifications. In so doing it is unavoidable in some cases that similar products which are on the market under other trade names may not be cited. No endorsement of named products is intended nor is criticism implied of similar products which are not mentioned. 